\title{
HYPERTROPHY OF THE TONGUE,
}

BEING

THE ACCOUNT OF A CASE OF THAT DISEASE, WHICH

WAS SUCCESSFULLY TREATED BY LIGATURE.

BY

J. HODGSON, Esa., F.R.S., PRESIDENT.

Received Feb. 8th.-Read Feb. 8th, 1853.

A little girl, named Harriet Howes, æt. 2 years, was admitted into the Birmingham General Hospital on the 15th of April, 1833. The following is the report of her case, which was taken by my friend, Mr. Bowman, of King's College, at the time a resident student in the hospital :

The tongue, enormously enlarged, hangs out of the mouth, and reaches below the chin. It completely fills up the orifice of the mouth, and doubles down the under lip, which is always in contact with the chin. If the mouth be opened, it may be perceived that the part of the tongue within the lips does not present any unnatural appearance, either as to size or colour, except that the papillæ are whitish and slightly raised from the surface. Immediately on emerging from the mouth the tongue is enlarged, both in breadth and thickness, and there is an evident constriction where it has pressed against the teeth and lips. The greatest transverse extent of the projecting portion is $2 \frac{3}{8}$ inches, and the length, anterior to the lips, rather more than 2 inches. The mother says that the child was born with a large tongue, and that when about two months old a leech was applied to the tip, which seems to have caused an increased action xxxvi. 
in the blood-vessels, for, since that time, the organ has continued to increase in size. Mr. Hodgson first saw the child about twelve months ago; she was then in very bad health ; the whole surface of the tongue was inflamed, excoriated, and extremely irritable. He did not then advise any operation, expecting that the child would not live many days; but her health improved, and she is now as strong as infants of her age generally are. The projecting portion of the tongue, however, exhibits vestiges of the inflammation. Externally to the mouth the papillæ are raised above the surface, and present the appearance of small pimples. The projecting part is of a deep red colour, dry and rough on the upper surface, where in places scabs or crusts have formed. The child could suck like other infants, and she can now eat and drink easily. She could talk when 16 months old, and now articulates nearly as well as children of her age. The chief inconvenience which she suffers is from the continual dribbling of saliva from her tongue and mouth. She can move the projecting part from side to side, or protrude it forward, and the muscular fibres appear to extend to its anterior extremity. The mother says that the tongue could be retracted into the mouth until the child was two months old, when the leech was applied, since which time it could not be even replaced within the lips. The anterior part of the lower jaw has been pressed out of its perpendicular, by the protruding growth, almost into a horizontal position, so that the lower incisor teeth project forwards, and their edges are not in the same line as those of the upper jaw.

On the 20th of April the protruding portion of the tongue was included in ligatures. A curved needle, armed with a strong double ligature, was passed through the organ in the median line, a little distance within the mouth, and then each ligature was tied as far back as possible, so as to leave a kind of tip or projection to the portion of tongue remaining in the mouth. The little patient did not appear to suffer that acute pain which was expected to have been caused by this operation; she ceased to cry as soon as the 
ligatures were tightened. She passed a quiet night, and was cheerful and lively on the following day; the protruding portion of the tongue was cold and purple; the part within the mouth was not at all inflamed or sore when touched.

April 21. The protruding portion has become warmer, probably from a partial return of the circulation, permitted by a loosening of the ligatures caused by diminution in the bulk of the organ, consequent upon the discharge of a quantity of serum; for, on slightly abrading the surface, blood oozed from the part. In consequence of this, Mr. Hodgson applied fresh ligatures, in the same manner and in the same situations as on the preceding day. This stopped the bleeding, and the part again became cold. There does not appear to be any untoward symptom. The mouth is frequently washed out, by means of a syringe, with yeast and water, to which a little tincture of myrrh is occasionally added.

22. - The part is still cold and black. There are no signs of inflammation in the mouth; the child seldom cries, and seems to be going on as well as possible. Ten, p.m. - Some degree of warmth has returned in the part anterior to the ligatures, and on rubbing the surface a slight bleeding took place from the sloughing part. The ligatures were accordingly renewed as before. During this proceeding the little patient did not appear to suffer any pain.

23. - The protruding portion of the tongue is black and cold; the circulation is altogether stopped in it; the slough has nearly separated; no inflammation in the mouth; no constitutional disturbance of any importance.

24. - The slough was removed this morning by cutting it away with the scissors anterior to the ligatures, which were quite loose and unattached, so that they came away immediately afterwards. The part that remains, although quite within the lips, is yet very thick. The horizontal position of the anterior part of the lower jaw and of the front teeth is now also very remarkable. The upper and lower jaws cannot, in front, be brought into contact, partly from this peculiar position and elongation of the 
lower jaw; and partly from the thickness of the end of the tongue, which projects upwards in the mouth. A little honey and borax was applied to the ulcerated surface from which the slough was detached.

April 26.-General health continues good. The tongue has much decreased in size, and the child can nearly close her lips.

28. - The child's health continuing good, and the mother being anxious to take her home, she left the hospital today. She can now close her lips. The ulcerated surface is nearly healed, and the tongue continues to decrease in size.

In June, 1835, two years after the operation, she was again seen. She was then much grown, and could talk and eat without the least inconvenience. Her health was good and her complexion ruddy. The tongue had undergone no enlargement or morbid change since the operation. The pointed tip or end was thick, and stood up in the mouth, but it caused neither pain nor inconvenience. The lower jaw still projected, and the front teeth of the two jaws could not be placed in apposition. 